\title{
Analytical model for estimating the production and composition of gas resulted through gasification
}

\author{
Lucian Mihăescu ${ }^{1}$, Ionel Pîșă ${ }^{1}$, Iulia Simion ${ }^{2 *}$ and Gabriel Paul Negreanu ${ }^{1}$ \\ ${ }^{1}$ Mechanics and Mechatronics Faculty, University Politehnica of Bucharest, Splaiul Independentei \\ 313, 060042 Bucharest (Romania) \\ ${ }^{2}$ Power Engineering Faculty, University Politehnica of Bucharest, Splaiul Independentei 313, 060042 \\ Bucharest (Romania)
}

\begin{abstract}
For the modelling of gasification processes, several models have been developed over the years. It is remarked that gasification calculation models of very high complexity entail some complications. Therefore, simpler mathematical representations of gasification characteristics and process behavior are required as a first step in addressing such systems. The preliminary calculation simplicity is needed form two perspectives: First - the pre-sizing of gasification installations, and second - the estimation of experimental or functional results. For this kind of topics, an adequate simplified model should be defined. Further, to validate the results it will be necessary to use complex calculation models. The model proposed in this paper addresses gasification with distributive air in the air distribution current, considering general concurrent flow of air fuel. Previous successful investigations, conducted by the present research team, are taken into account within model definition stages. Thus, the work presented here provides useful advances in the field of mathematical modeling of gasification processes. The originality of the model consists in its easy computational accessibility, which allows the approach of technological optimizations, such as the variation of excess air and fuel composition.
\end{abstract}

Key words: biomass combustion, biomass gasification, energy recovery, modeling of gasification

\section{Introduction}

Performing or testing the functionalities of a gas generator depends on input obtained from the application of calculation models. The information thus obtained can be used in some cases.

Lately, the appearance of very complex calculation models which require time for the improvement of operations or for the previous processing of data is noticeable.

*Contact person: E-mail address julia.simion@gmail.com, 
The existence of simple calculation models proves useful, even if the final accuracy shows some deviations. In many studies the predicted equilibrium compares reasonably well with the results observed in experiments and in other cases the deviation is small enough. The achievement of thermodynamic equilibrium for the multitude of reactions that take place in the gasifier, has a particular importance. The idle time in various temperature zones influences the thermodynamic equilibrium considered in fact reached by all calculation models.

Essentially, a calculation model for a gasifier, must pass through the steps inside the gas generator, namely [1] [2]:

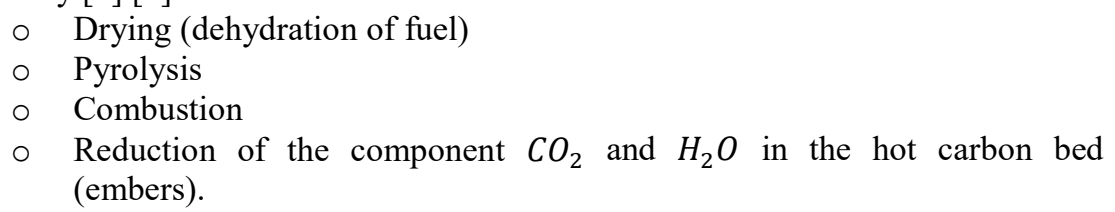

Even if the gasifier as a whole is autothermal, the first two processes are endodermal.

The temperature level in the main zones of gas generator reflects the dynamics of the development of specific thermochemical processes.

In the gasification process, the biomass is heated to a high temperature, usually more than $700^{\circ} \mathrm{C}$, producing a series of physical and chemical changes, which result in the development of volatile products plus solid carbonaceous residues. [3]

Gasification is one of the most economical and common applications for the use of biomass, which due to its abundant presence in different countries, is of great interest as a source of renewable energy. During gasification the mixture of biomass and gasifying agents (air, steam, carbon dioxide or oxygen) are bring to high temperatures, in order to obtain a fuel gas known as synthesis gas or simply syngas. [4]

The synthesis gas is composed of a set of gases and each of them is very important depending on the specific application of the synthesis gas. For this reason, there is a lot of research on modeling the composition of syngas obtained from both fixed bed gasifiers and fluidized bed gasifiers [5]. In a recent comprehensive review was reported that approximately $60 \%$ of all published gasification studies with models used only equilibrium models and just $40 \%$ used, or included, non-equilibrium deviations. [6]

The model developed in this research is for the gasification of biomass with air inlet only in the combustion zone.

\section{Biomass gasification model}

The information on the thermochemical processes in the gas generator, request the elementary analysis of the fuel in the form [7]:

$$
C^{i}+H^{i}+S_{c}^{i}+O^{i}+N^{i}+W^{i}+A^{i}=100
$$

Where the elements: carbon $C^{i}$, hydrogen $H^{i}$, sulfur $S_{c}^{i}$, oxygen $O^{i}$, nitrogen $N^{i}$, moisture $W^{i}$ and ash $A^{i}$ are in mass proportions. For biogas, the absence of sulfur is allowed $\left(S_{c}^{i}=0\right)$.

The Figure 1 shows the physic-chemical model for the analyzed gas generator, with air supply in the combustion zone. [8] 


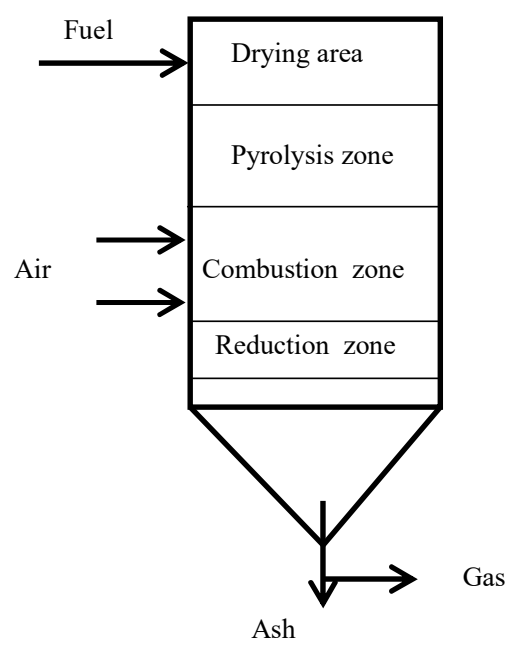

Fig 1. The thermochemical phases in a gasifier with air inlet

In the combustion zone the drying process reaches temperatures ranging between $70-200^{\circ} \mathrm{C}$. Starting with $200^{\circ} \mathrm{C}$ for biomass, the release of volatiles begins. After drying, the fuel composition becomes (it was also considered the removal of the mineral mass):

$$
C^{a n h}+H^{a n h}+O^{a n h}+N^{a n h}=100[\%]
$$

Participations from the anhydrous state are obtained from those of the initial state by the correction with the factor $\varphi_{1}$ :

$$
\begin{gathered}
\varphi_{1}=\frac{100}{100-W^{i}-A^{i}} \\
C^{a n h}=C^{i} \times \varphi_{1}, \quad H^{a n h}=H^{i} \times \varphi_{1}, \quad O^{a n h}=O^{i} \times \varphi_{1}, \quad N^{a n h}=N^{i} \times \varphi_{1}[\%]
\end{gathered}
$$

If the mass of the intake of fuel (flow) in gas generator is $m_{1}$, the mass of pyrolysis will become:

$$
m_{2}=m_{1} \times \frac{1}{\varphi_{1}}\left[\frac{k g}{s}\right]
$$

In the pyrolysis phase, volatile materials are released, which include the components: $\mathrm{CO}$, $\mathrm{CO}_{2}, \mathrm{CH}_{4}, \mathrm{H}_{2}$. Pyrolysis perform in the range of $200-700^{\circ} \mathrm{C}$. In this phase there is, as well, a release of liquid tar.

The amount of gas and tar released depends on the average temperature level in the pyrolysis zone [8] [9].

The mass quantity of gas $m_{3}$ released can be estimated from the mass $m_{2}$ by the function $\varphi_{2}$. The transformation functions in the pyrolysis process come from the literature [9].

$$
\begin{gathered}
m_{3}=m_{2} \times \varphi_{2}\left[\frac{\mathrm{kg}}{\mathrm{s}}\right] \\
\varphi_{2}=0.01\left(1.12 T^{2} \times 10^{-4}-0.058 T+30.77\right)
\end{gathered}
$$

The mass amount of tar $m_{4}$ removed from the mass $m_{2}$ can be determined by the relation [9]: 


$$
\begin{gathered}
m_{4}=m_{2} \times \varphi_{3}\left[\frac{\mathrm{kg}}{\mathrm{s}}\right] \\
\varphi_{3}=0.01\left(-1.38 T^{2} \times 10^{-4}+0.12 T+12.64\right)
\end{gathered}
$$

The composition of the released gas can be estimated with the relations [9]:

mass proportion of $\mathrm{CO}$ :

$$
g_{C O}=0.01\left(-2.65 T^{2} \times 10^{-4}+0.27 T-32.71\right) \quad[\%]
$$

mass proportion of $\mathrm{CH}_{4}$ :

$$
g_{\mathrm{CH}_{4}}=0.01\left(6.69 T^{2} \times 10^{-5}-0.037 T+4.28\right) \quad[\%]
$$

mass proportion of $\mathrm{H}_{2}$ :

$$
g_{H_{2}}=0.01\left(7.0 T^{2} \times 10^{-5}-0.0371 T+5.111\right) \quad[\%]
$$

The difference is obtained by the mass proportion of $\mathrm{CO}_{2}$ :

$$
g_{\mathrm{CO}_{2}}=1-\left(g_{\mathrm{CO}}+g_{\mathrm{CH}_{4}}+g_{\mathrm{H}_{2}}\right)[\%]
$$

The massive amounts of gas will be:

$$
\begin{gathered}
m_{\mathrm{CO}}=m_{3} \times g_{\mathrm{CO}}\left[\frac{\mathrm{kg}}{\mathrm{s}}\right] \\
m_{\mathrm{CH}_{4}}=m_{3} \times g_{\mathrm{CH}_{4}}\left[\frac{\mathrm{kg}}{\mathrm{s}}\right] \\
m_{\mathrm{H}_{2}}=m_{3} \times g_{\mathrm{H}_{2}}\left[\frac{\mathrm{kg}}{\mathrm{s}}\right] \\
m_{\mathrm{CO}_{2}}=m_{3}-m_{\mathrm{CO}}-m_{\mathrm{CH}_{4}}-m_{\mathrm{H}_{2}}\left[\frac{\mathrm{kg}}{\mathrm{s}}\right]
\end{gathered}
$$

After pirolysis process, the gasification process involves the oxidation of carbon with the air and the thermal reduction of carbon dioxide by carbon.

Mass of carbon participating in the reaction [10]:

$$
m_{5}=m_{2}-m_{3}-m_{4}\left[\frac{k g}{s}\right]
$$

The amount of air $m_{6}$ depends on the excess air used $\lambda$. Usually, in order to control the mass of carbon participating in the reduction process, the excess air wiil be less than 1 $(\lambda<1)$. On burning carbon, the theoretical volume of combustion air is $9.03 \frac{\mathrm{Nm}^{3}}{\mathrm{~kg}}$.

For excess air $\lambda$, the volume of humid air introduced will be:

$$
V_{a}=9.03 \times \lambda \times m_{5} \quad\left[\frac{\mathrm{Nm}^{3}}{\mathrm{~kg}}\right]
$$

Air mass corresponding to the volume $V_{a}$ will be:

$$
m_{a}=6.4 \times \lambda \times m_{5}\left[\frac{\mathrm{kg}}{\mathrm{kg}}\right]
$$

Excess air recommended value is in the range of $\lambda=0.25-0.45$.

The mass of oxidized carbon will be:

$$
m_{6}=\lambda \times m_{5}\left[\frac{k g}{s}\right]
$$

The emission of $\mathrm{CO}_{2}$ at oxidation of the carbon unit results from the stoichiometry of combustion: 


$$
V_{\mathrm{CO}_{2}}=1.867 \quad\left[\frac{\mathrm{Nm}^{3}}{\mathrm{~kg}}\right]
$$

The emission of $\mathrm{CO}_{2}$ from the amount of carbon existing in the reduction zone will be:

$$
m_{7}=1.867 \times \lambda \times m_{5} \quad\left[\frac{\mathrm{kg}}{\mathrm{s}}\right]
$$

The nitrogen content in the gas will be:

$$
V_{N_{2}}=0.79 V_{a}=7.14 \times \lambda \times m_{5} \quad\left[\frac{\mathrm{Nm}^{3}}{\mathrm{~s}}\right]
$$

The reduction reaction $\mathrm{C}+\mathrm{CO}_{2}=2 \mathrm{CO}$ depends on the system pressure and the temperature level. The reaction is endothermic.

According to Boudouard's law, the ratio of the transformation of $\mathrm{CO}_{2}$ into $\mathrm{CO}$ is presented in table no. 1

Table 1. Relation $\mathrm{CO} /$

\begin{tabular}{|c|c|c|}
\hline$t\left[{ }^{\circ} \mathrm{C}\right]$ & $\mathrm{CO}[\%]$ & $\mathrm{CO}_{2}[\%]$ \\
\hline 450 & 0.6 & 99.4 \\
\hline 550 & 10.7 & 89.3 \\
\hline 650 & 39.8 & 60.2 \\
\hline 800 & 93 & 7.0 \\
\hline 925 & 96 & 4.0 \\
\hline
\end{tabular}

Analytically, the proportion of $\mathrm{CO}$ obtained by reducing the gas $\mathrm{CO}_{2}$ is determined by the relation

Where:

$$
k_{p}=\frac{4 p a^{2}}{1-a^{2}}
$$

- $a=\frac{\mathrm{CO}}{\mathrm{CO}_{2}+\mathrm{C}}$

- $p$-reactor pressure $[b a r]$

- $k_{p}$ - the constant of Boudouard's law, which is determined using the data in table no. 2

Table 2. Variation of $\boldsymbol{K}_{\boldsymbol{p}}$ with temperature

\begin{tabular}{|c|c|}
\hline Temperature $[K]$ & $\lg k_{p}$ \\
\hline 500 & -4.603 \\
\hline 1000 & 0.415 \\
\hline 1500 & 2.240 \\
\hline
\end{tabular}

The content of carbon monoxide after combustion and reduction with carbon will be:

$$
m_{8}=a \times m_{7} \quad\left[\frac{k g}{s}\right]
$$

The content of carbon dioxide in the bed will be:

The reactions take place in the carbon bed:

$$
m_{9}=(1-a) m_{7} \quad\left[\frac{k g}{s}\right]
$$

$$
\begin{gathered}
C+\mathrm{O}_{2}=\mathrm{CO}_{2}+34,096[\mathrm{~kJ}] \\
C+1 / 2 \mathrm{O}_{2}=\mathrm{CO}+10,276[\mathrm{~kJ}]
\end{gathered}
$$




$$
\begin{gathered}
\mathrm{C}+\mathrm{CO}_{2}=2 \mathrm{CO}-13,544[\mathrm{~kJ}] \\
\mathrm{C}+\mathrm{H}_{2} \mathrm{O}=\mathrm{CO}+\mathrm{H}_{2}-9,909[\mathrm{~kJ}] \\
\mathrm{C}+2 \mathrm{H}_{2}=\mathrm{CH}_{4}+6,285[\mathrm{~kJ}] \\
\mathrm{CO}+3 \mathrm{H}_{2}=\mathrm{CH}_{4}+\mathrm{H}_{2} \mathrm{O}+17,004[\mathrm{~kJ}]
\end{gathered}
$$

Hydrogen is produced only by the reaction (30). Methane is produced by two reactions from equations (31) and (32). For reaction (30), the reaction rate constant can be determined by the relation [11] [9] [12]:

$$
K_{1}=e^{\left[\frac{4276}{T}-3.961\right]}
$$

For reaction (31), the reaction rate constant can be determined by the relation [13]:

$$
\begin{aligned}
\ln K_{2}=\frac{7,082.842}{T} & -6.567 \ln T+\frac{7.467}{2} T 10^{-3}-\frac{2.167}{6} T^{2} 10^{-6}+\frac{0.702}{2 T^{2}} \\
& +32.541
\end{aligned}
$$

The relation can be reduced to form:

with

$$
\ln K_{2}=f(T)
$$

$$
K_{2}=e^{f(T)}
$$

For reaction (31) the speed constant will be [14] [15] [9] [16]:

$$
K_{3}=1.198 \times 10^{13} e^{-\frac{26830}{T}}
$$

Reaction (31) occurs when steam is used for gasification, in which case the volume of water in reaction (29) allows the emission of hydrogen, which allows the operation of the reaction around the values of the reaction constants $K_{2}$ and $K_{3}$.

In the study, not using the steam injection eliminates the reaction (32), because the estimated amount of water is consumed in the reaction (29), which has a much higher speed constant.

The stoichiometry of the reaction (29) requires the following amounts of substance [10]:

$$
12 \mathrm{kgC}+22.4 \mathrm{Nm}^{3} \mathrm{H}_{2} \mathrm{O}=22.4 \mathrm{Nm}^{3} \mathrm{CO}_{2}+22.4 \mathrm{Nm}^{3} \mathrm{H}_{2}
$$

The amount of water vapor $V_{\mathrm{H}_{2} \mathrm{O}}$ in the carbon reaction zone imposed by that achieved in the drying process:

$$
V_{\mathrm{H}_{2} \mathrm{O}}=1.242 \frac{W^{i}}{100}\left[\frac{\mathrm{Nm}^{3} \mathrm{H}_{2} \mathrm{O}}{\mathrm{kg} \text { fuel }}\right]
$$

Replacing the relation (39) in (38) will result in a carbon consumption of $0.0066 W^{i}$ $[\mathrm{kg} / \mathrm{kg}]$ and a hydrogen emission of $1.242 \frac{\mathrm{W}^{i}}{100} \mathrm{Nm}^{3} / \mathrm{kg}$.

The total volume of hydrogen, formed in the pyrolysis phase expressed by relation (15) and by reducing the amount of water expressed by relation (30) will be:

$$
V_{H_{2}}^{*}=\frac{m_{H_{2}}}{\rho_{H_{2}}}+1.242 \frac{W_{i}}{100}\left[\frac{N^{3}}{s}\right]
$$


According to relation (31) the emission of $\mathrm{CH}_{4}$ with the maximum value $0.5 \times V_{\mathrm{H}_{2}}$ will depend on the ratio of the reaction constants $K_{2} / K_{1}$, so that it becomes:

$$
V_{\mathrm{CH}_{4}}=0.5 \frac{K_{2}}{K_{1}} V_{H_{2}}^{*} \quad\left[\frac{N m^{3}}{s}\right]
$$

And the volume of hydrogen $V_{\mathrm{H}_{2}}$ is reduced to the quantity:

$$
V_{H_{2}}=\left(1-0.5 \frac{K_{2}}{K_{1}}\right) V_{H_{2}}^{*} \quad\left[\frac{N m^{3}}{s}\right]
$$

The gas from the gas generator, at the end of the thermochemical processes will have the composition:

$$
\begin{gathered}
V_{C O}=\frac{m_{C O}}{\rho_{C O}}+a \frac{m_{7}}{\rho_{C O}}\left[\frac{N^{3}}{s}\right] \\
V_{C_{2}}=\frac{m_{C O_{2}}}{\rho_{C O_{2}}}+(1-a) \frac{m_{7}}{\rho_{C O_{2}}}\left[\frac{N m^{3}}{s}\right] \\
V_{H_{2}}=\left(1-0.5 \frac{K_{2}}{K_{1}}\right)\left[\frac{m_{H_{2}}}{\rho_{H_{2}}}+1.242 \frac{W_{i}}{100}\right]\left[\frac{N^{3}}{s}\right] \\
V_{C H_{4}}=0.5 \frac{K_{2}}{K_{1}}\left[\frac{m_{H_{2}}}{\rho_{H_{2}}}+1.242 \frac{W_{i}}{100}\right]\left[\frac{N m^{3}}{s}\right] \\
V_{N_{2}}=7.05 \times \lambda \times m_{5}\left[\frac{N m^{3}}{s}\right]
\end{gathered}
$$

The volume of gas from the gas formed by the thermochemical reactions will be:

$$
V_{g}=V_{C O}+V_{\mathrm{CO}_{2}}+V_{\mathrm{H}_{2}}+V_{\mathrm{CH}_{4}}+V_{\mathrm{N}_{2}}\left[\frac{\mathrm{Nm}^{3}}{\mathrm{~s}}\right]
$$

From this relation the participation of the gas in the gas generator can be determined:

$$
\begin{gathered}
\mathrm{CO}=\frac{V_{C O}}{V_{g}} \times 100 \quad[\%] \\
\mathrm{CO}_{2}=\frac{V_{\mathrm{CO}_{2}}}{V_{g}} \times 100 \quad[\%] \\
\mathrm{H}_{2}=\frac{V_{\mathrm{H}_{2}}}{V_{g}} \times 100 \quad[\%] \\
\mathrm{CH}_{4}=\frac{V_{C H_{4}}}{V_{g}} \times 100 \quad[\%] \\
\mathrm{N}_{2}=100-\left(\mathrm{CO}+\mathrm{CO}_{2}+\mathrm{H}_{2}+\mathrm{CH}_{4}\right) \quad[\%]
\end{gathered}
$$

The lower heating value of the gas of gasifier $H_{i, g}$ is determined by the relation:

$$
H_{i, g}=0.01\left(\mathrm{CO} \times H_{i, C O}+H_{2} \times H_{i, H_{2}}+\mathrm{CH}_{4} \times H_{i, C H_{4}}\right) \quad\left[\frac{\mathrm{kJ}}{\mathrm{Nm}^{3}}\right]
$$

where $H_{i, C O}, H_{i, H_{2}}, H_{i, C H_{4}}$ is the lower heating value for carbon monoxide, respectively for hydrogen and methane.

The efficiency of the gasifier will be defined by the ratio between the thermal power of the gasifier and that for the initial fuel: 


$$
\eta=\frac{V_{g} \times H_{i, g}^{i}}{m_{1} \times H_{i}^{i}} \times 100
$$

where $H_{i}^{i}$ is the lower heating value of the fuel subjected to gasification.

\section{Thermal field estimation}

A simple model can take in consideration:

- heat absorption for dehydration;

- heat absorption in the pyrolysis phase;

- heat emission on carbon oxidation, with the formation of $\mathrm{CO}_{2}$;

- heat absorption when converting carbon dioxide to carbon monoxide;

- heat absorption when heating the mineral mass

the model did not consider the heat emission for the reduction reactions, considered in a small proportion and the heat loss to the external environment. The air was considered at reference temperature $t_{1}$.

In the design of the gas generator, the gradual air intlet was considered, starting with the ignition temperature of the carbon, the evolution of the temperatures in the case of the gas generator will be of the form:

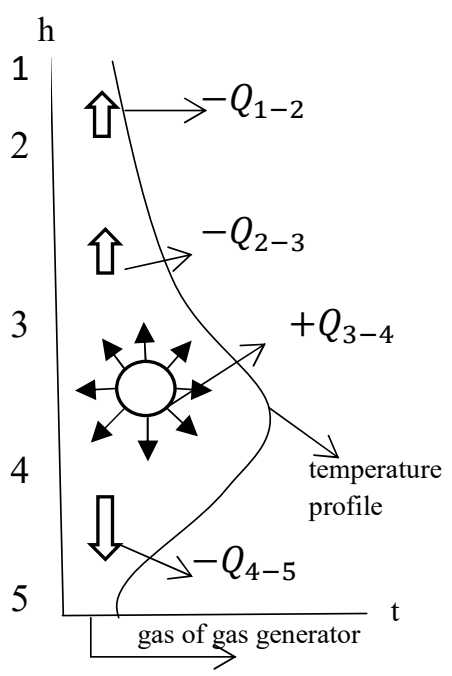

Fig. 2. The evolution of temperature in the gas generator body

Heat emitted by the combustion of fixed carbon (charred coal) will be:

$$
Q_{3-4}=m_{6} \times H_{i, c}^{i} \quad[k W]
$$

Where $H_{i, c}^{i}$ is the lower heating value of carbon, measured in $\left\lceil\frac{\mathrm{kJ}}{\mathrm{kg}}\right]$.

The output of this heat is:

- $\quad$ heating the vaporization of water, $Q_{1-2}[k W]$;

- $\quad$ heating for pyrolysis, $Q_{2-3}[k W]$

- cooling produced in the carbon reduction space, $Q_{4-5}[\mathrm{~kW}]$;

Finally, the temperature of the gas gasifer leaving the installation is obtained.

For biomass gasification, there is no need for external heating of the gasifier. 
In this paper there is an appendix where a result of the composition of the gas obtained by the developed model is exemplified, for a certain temperature level existing in the specific areas of the gas.

\section{Conclusions}

- The model has taken in account the achievement of thermodynamic equilibrium for all existing stages into the gas generator processes. These hypotheses are sufficiently reached for the gasification of biomass, as shown by all the literature.

- The model led to a decrease in the amount of nitrogen $\left(N_{2}\right)$ found in the gas within the gas generator compared to most other experimental data. The development of a thermal model for the thermochemical phases will contribute to the correction of these values. Gas flow rate influences both the thermal field and the reaction time.

- The gasification process was considered as a completely distinct succession of subprocesses, without any interference between them. This simplified the calculation model to the detriment of accuracy. However, the numerical application demonstrated its viability for the initial assumptions, related to the nature of the fuel and distinct phases of drying, pyrolysis and gasification by reducing some substances.

- The theoretical data obtained were compared with those from previous experiments and presented in the paper "Researches on biofuels gasification using the Lurgi process with homogeneous air inlet over the combustion space", the existing deviation will be used to optimize both directions - biomass gasification experiments, corrections on the calculation model. The model developed can be compared with the models developed in the paper "A mathematical model of biomass downdraft gasification with an integrated pyrolysis model" [17].

\section{Appendix}

The results of a numerical application in order to preliminary validation of the developed model.

Elementary analyze: $W^{i}=20 \% ; A^{i}=5 \% ; O^{i}=25 \% ; N^{i}=1 \% ; H^{i}=5 \%, C^{i}=44 \%$

Fuel flow: $m_{1}=1 \frac{\mathrm{kg}}{\mathrm{s}} ; \varphi_{1}=1.33 ; m_{2}=0.75 \frac{\mathrm{kg}}{\mathrm{s}}$;

For $T=700 K ; \varphi_{2}=0.45 ; \varphi_{3}=0.29 ; m_{3}=0.337 \frac{\mathrm{kg}}{\mathrm{s}} ; m_{4}=0.217 \frac{\mathrm{kg}}{\mathrm{s}} ; m_{C O}=0.087 \frac{\mathrm{kg}}{\mathrm{s}}$;

$m_{\mathrm{CH}_{4}}=0.037 \frac{\mathrm{kg}}{\mathrm{s}} ; \quad m_{\mathrm{H}_{2}}=0.043 \frac{\mathrm{kg}}{\mathrm{s}} ; \quad m_{\mathrm{CO}_{2}}=0.17 \frac{\mathrm{kg}}{\mathrm{s}} ; m_{5}=0.196 \frac{\mathrm{kg}}{\mathrm{s}} ; \quad \lambda=0.4 ; \quad m_{6}=$

$0.078 \frac{\mathrm{kg}}{\mathrm{s}} ; V_{a}=0.696 \frac{\mathrm{m}_{\mathrm{N}}^{3}}{\mathrm{~kg}} ; m_{7}=0.14 \frac{\mathrm{kg}}{\mathrm{s}}$;

Temperature in bed $800^{\circ} \mathrm{C} ; a=0.93$

For temperature of $1,000^{\circ} \mathrm{K}, K_{1}=1.37, K_{2}=0.4$

$V_{C O}=0.137 \frac{\mathrm{m}^{3}}{\mathrm{~s}} ; \quad V_{\mathrm{CO}_{2}}=0.09 \frac{\mathrm{m}^{3}}{\mathrm{~s}} ; \quad V_{\mathrm{H}_{2}}=0.51 \frac{\mathrm{m}^{3}}{\mathrm{~s}} ; \quad V_{C_{4}}=0.1 \frac{\mathrm{m}^{3}}{\mathrm{~s}} ; \quad V_{\mathrm{N}_{2}}=0.57 \frac{\mathrm{m}^{3}}{\mathrm{~s}} ;$

$V_{g}=1.503 \frac{\mathrm{m}^{3}}{\mathrm{~s}}$

The composition of gas of the gas generator is:

$\mathrm{CO}=11.5 \% ; \mathrm{CO}_{2}=5.9 \% ; \mathrm{H}_{2}=37.9 \% ; \mathrm{CH}_{4}=6.6 \% ; \mathrm{N}_{2}=38 \%$ 


\section{References}

1. D. Baruah and D. Baruah, "Modeling of biomass gasification: a review," Renew Sustain Energy Rev, p. 39:806-15, 2014.

2. [A. Bridgwater, "The technical and economic feasibility of biomass gasification for power generation," Fuel, p. 74(5):631-53., 1995.

3. Elif Kirtay, "Recent advance in production of hydrogen from biomass," Energy conversion and management, vol. 52, no. pp.1778-1789, 2011.

4. P. Basu, “Biomass gasification and pyrolysis,” vol. 1st ed. , 2010.

5. Jordan Amaro, Diego Jhovanny Mariños Rosadoa, Andrés Z. Mendiburu, Leila Ribeiro dos Santos and João A. de Carvalho Jr, "Modeling of syngas composition obtained from fixed bed gasifiers using Kuhn-Tucker multipliers,” vol. 287, no. 119068, 2021.

6. Safarian S, Richter C. A and Unnporsson R, "A review of biomass gasification modelling.," Renew Sustain Energy Rev, vol. 110, p. 378-91, 2019.

7. I. G. Carabogdan, A. Badea, L. Ionescu, A. Leca, I. Nistor and I. Cserveny, Industrial termical installtion, Bucharest: ET, 1978.

8. H.-J. Huang and S. Ramaswamy, "Modeling biomass gasification using thermodynamic equilibrium approach,” Appl Biochem Biotechno, p. 154(1-3):14-25., 2009.

9. M. Trninić , A. Jovović and D. Stojiljković , “A steady state model of agricultural waste pyrolysis: a mini review.," Waste Manage Res, p. 34(9):851-65, 2016.

10. P. Nicolae, C. Cazacu, L. Mihaescu, L. Popescu and D. Biclesanu, Modernization of combustion installations for industrial boilers, Bucharest: Tehnical, 1993.

11. T. Patra and P. Sheth, "Biomass gasification models for downdraft gasifier: a stateofthe- art review," Renew Sustain Energy Rev, p. 50:583-93, 2015.

12. Barman NS, Ghosh S and De S, "Gasification of biomass in a fixed bed downdraft gasifier - a realistic model including tar,” Bioresour Technol, p. 107:505-11., 2012.

13. [Zainal ZA, Ali R, Lean CH and Seetharamu KN, "Prediction of performance of a downdraft gasifier using equilibrium modeling for different biomass materials," Energy Convers Manage , p. 42(12):1499-515., 2001.

14. M. Puig-Arnavat, J. Bruno and Coronas A, "Review and analysis of biomass gasification models,” Renew Sustain Energy Rev, p. 14(9):2841-51, 2010.

15. V. Sikarwar, M. Zhao, P. Clough, J. Yao, X. Zhong and M. Memon, “An overview of advances in biomass gasification,” Energy Environ Sci, p. 9:2939-77, 2016. 
16. Bottino A, Comite A, Capannelli G, Di Felice R and Pinacci P, "Steam reforming of methane in equilibrium membrane reactors for integration in power cycles," Catal Today, p. 118(1-2):214-22., 2006.

17. T. Marta , S. Dragoslava, S. Øyvind, W. Liang, J. Aleksandar and M. Nebojsa , “A mathematical model of biomass downdraft gasification with an integrated," Fuel, vol. 265 , p. $116867,2020$.

18. G. Lazaroiu, L. Mihaescu, G. Negreanu, I. Simion and D.A. Ciupageanu, "Researches on biofuels gasification using the Lurgi process with homogeneous air inlet over the combustion space," E3S Web of Conferences, vol 180/2020, DOI: https://doi.org/10.1051/e3sconf/202018001011. 